\title{
Hybrid electric vehicle car body drag analysis using computational fluid dynamics
}

\author{
D. Ramasamy*, K. Mohanesan, K. Kadirgama, M.M. Noor and M.M. Rahman \\ Faculty of Mechanical Engineering, Universiti Malaysia Pahang \\ 26300 UMP, Kuantan, Pahang, Malaysia. \\ Phone: +609-4246359 Fax: +609-4242202. \\ *Email: deva@ump.edu.my
}

\begin{abstract}
Aerodynamics drag was considered for giving better efficiency for a car on the road. The development of drag on a vehicle body was studied. The main objective was to determine the maximum drag occurring on the car body drag of the hybrid electric vehicle (HEV). The analysis was conducted on the car speed ranging between $40 \mathrm{~km} / \mathrm{h}$ to $110 \mathrm{~km} / \mathrm{h}$ using pressure points at various parts of the car. The car body was modelled in CAD using the mass and momentum equations discretized for an analysis. The technique to estimate the drag used was input of car body-drag (CFD) and exporting it to finite element analysis (FEA) to find the value of aerodynamics drag in terms of drag forces and drag coefficient. The values were validated with actual pressure reading from pressure probes on the car body. The result showed that contour and trajectories plots were also used to analyse the characteristics of streamlines flow or boundary layer occurred on the body of this model, especially for the forebody, upper body and rear body. The maximum rise of aerodynamics drag occurred between velocities of $80 \mathrm{~km} / \mathrm{h}$ and $90 \mathrm{~km} / \mathrm{h}$ which was about $5.04 \%$ increase of drag coefficient. Further analysis is required with wind tunnels.
\end{abstract}

Keywords: Modelling; simulation; CFD; FEM; drag force; drag coefficient.

\section{INTRODUCTION}

Aerodynamics issue is very critical for car makers. The demands for more efficient and faster car are always a priority for the marketing strategy. The importance of aerodynamics to a Hybrid Electric Vehicle (HEV) is the determination of drag estimation to know the car's performance on the road against air resistance. It can be used to improve stability, noise and fuel consumption [1-7]. Many car makers formulate research and continue to develop the HEV models that are focused on higher propulsion efficiency in order to integrate the energy saving by reducing the rolling resistance of wheel and the drag by aerodynamically losses. The effect creates a more fuel-efficient design of the body. The design will help customers to save fuel usage which is in scarcity. The savings are also on the environment as less fuel usage reduces emissions in a two-prong benefit. The Proton Iswara Hatchback body was used by the group to modify the conventional power train to the hybrid power train. As drag is increased, the more power of the car is used to do work to push the air. This in turn reduces the power train efficiency [8]. Therefore, passenger car's body needs to be studied in terms of aerodynamics losses. To understand the aerodynamics of the HEV model, flow visualisation is the best technique. It is usually done with wind tunnel [9]. However, in this paper Computational Fluid 
Dynamics (CFD) analysis was used as the technology of computer simulation to estimate the drag because it is cheaper than the conventional technique.

Latest car design is used to improve the drag and increase the car speed. The car has been optimised by the manufacturer by having rounded body corners, raked windows and hatchback as found by $[10,11]$. However, the passenger car must be large enough to accommodate people, the power train and support components, making it extremely difficult to realise an aerodynamically ideal body shape. The car body is therefore, obliged to have an aerodynamically bluff, not an ideal streamline shape as seen on fish and birds [12]. Such a body shape is inevitably inefficient in nature to reduce drag. The shape normally causes a flow separation from the rear end of the body. Flow visualisations can help to understand the nature of the separation flow and prediction of drag [13]. Generally, tuft and wind tunnels can be used to visualise the flow. The purposes of the study are to develop the drag estimation on a vehicle body and to visualise the flow pattern from CFD analysis. The maximum points of the drag are analysed for further development in wind tunnels and real car models in the future.

\section{METHODS AND MATERIALS}

\section{Modelling of HEV Body}

The CFD was used to produce satisfactory results for designers before the actual car fabrication. The car was dismantled and most of the components were reduced. The aim was to reduce the overall weight of the car. As an electric vehicle, the engine was removed and replaced with an electric motor as the new drive train of the car as in Figure 1. The components of the car are shown with the battery pack being charged by the internal combustion engine and the main drive train is from the motor assembly. It was designed with efficiency in mind. The design is a series of hybrid vehicle shown in which energy flow from fuel tank to engine to charge the batteries which run on an electric motor quoted by [14]. The importance of the research was to incorporate energy saving by various methods of reducing traction friction from the wheel and also to reduce the drag by aerodynamic losses. Aerodynamic losses generally increase in quadratic with speed from fluid mechanics.

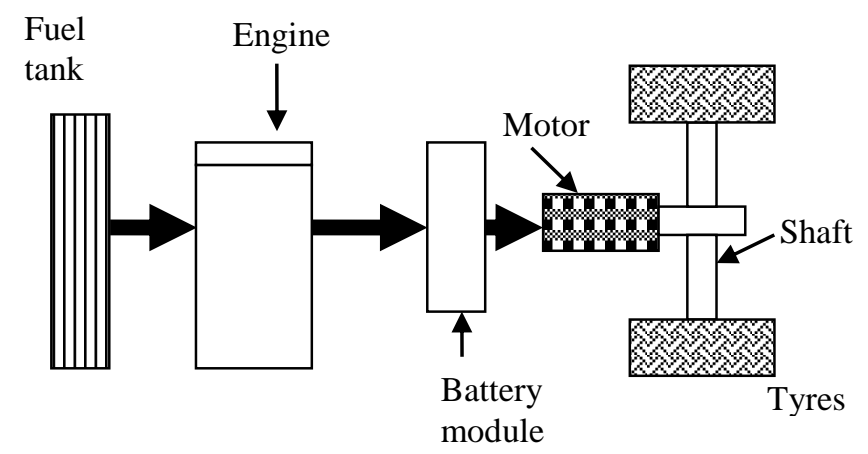

Figure 1. Hybrid Power train in UMP of a Proton Iswara

A model of the vehicle body was made by using data measured in actual car model in the vehicle lab, from Drayton [15] and also from raw measurements using a combination of meter ruler, L-Ruler, vernier calipers and strings for radius [16, 17]. The 
measurements were compared to Proton manufacturer data as shown in Table 1. The model is shown in Figure 2.

Table 1. PROTON manufacturer data.

\begin{tabular}{ll}
\hline Specification & Data \\
\hline Maximum height & $: 1360 \mathrm{~mm}$ \\
Maximum width & $: 1655 \mathrm{~mm}$ \\
Maximum length & $: 4110 \mathrm{~mm}$ \\
Wheelbase & $: 2380 \mathrm{~mm}$ \\
Track: (front)/ (rear) & $: 1406 \mathrm{~mm} 1356 \mathrm{~mm}$ \\
Curb weight & $: 970 \mathrm{Kg}$ \\
Gross vehicle weight & $: 1360 \mathrm{Kg}$ \\
Engine & $: 4 \mathrm{G} 13 \mathrm{P}, 12 \mathrm{~V} \mathrm{SOHC}$ \\
Bore x stroke & $: 71 \mathrm{~mm} \mathrm{X} 82 \mathrm{~mm}$ \\
Total displacement & $: 1299$ \\
Maximum output & $: 62 \mathrm{kN} / 6000 \mathrm{rpm}$ \\
Maximum torque & $: 109 \mathrm{Nm} / 4000 \mathrm{rpm}$ \\
\hline
\end{tabular}
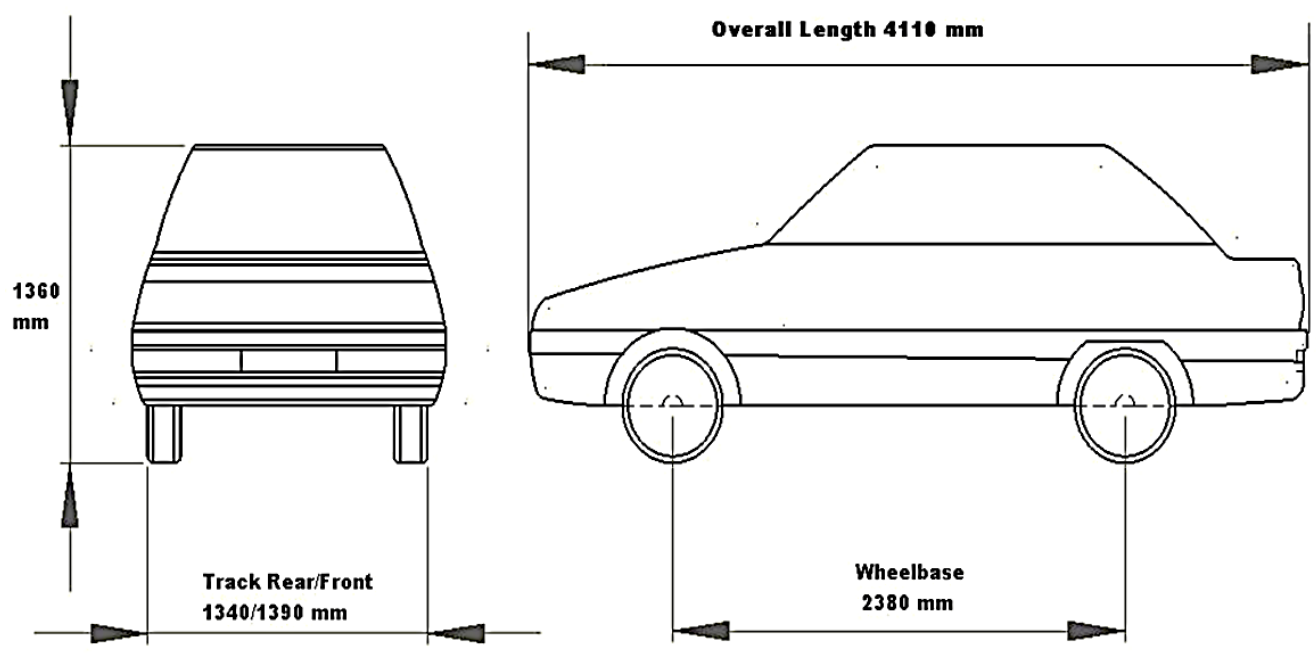

Figure 2. HEV Model dimensions.

In a common moving car, there are constant forces acting to the car in which cause drag. It is dependent on the geometry of the body, motion of the body and the fluid in which it is travelling. The general forces found are drag and lift as shown in Figure 3. This can be proved from fluid mechanics $[18,19]$ as Eq. (1).

$$
\begin{gathered}
F_{D}=C_{D} \frac{1}{2} \rho V^{2} A \\
F_{L}=C_{L} \frac{1}{2} \rho V^{2} A
\end{gathered}
$$



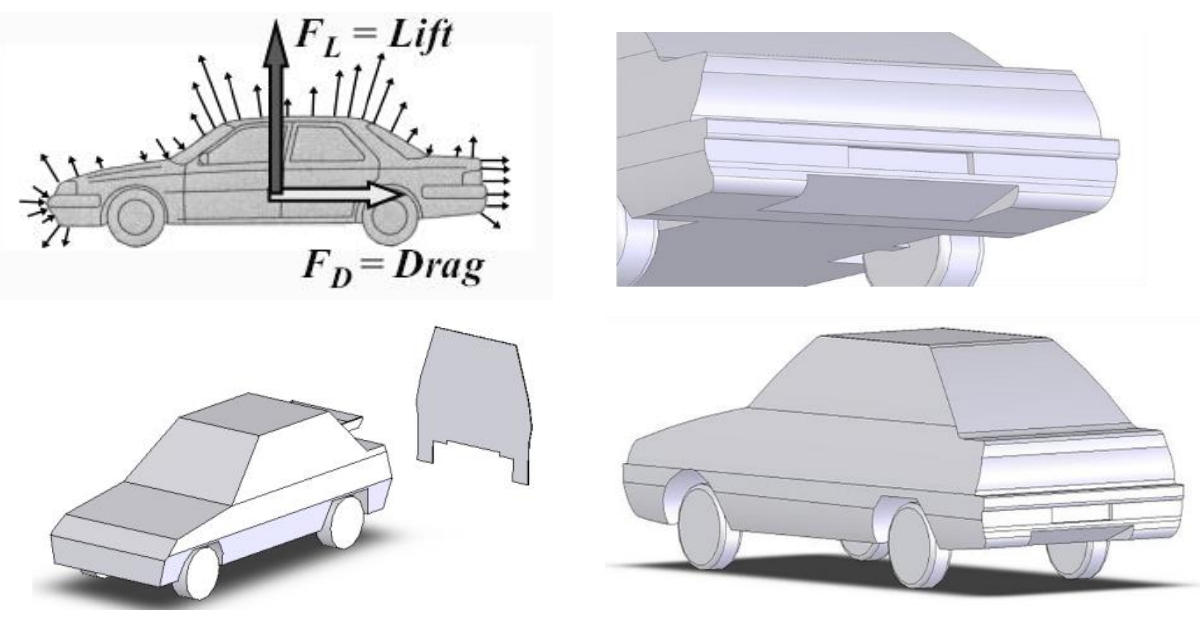

Figure 3. Distribution of lift and drag for a car with frontal area.

where, $F_{D}$ and $F_{L}$ are both drags and lift forces, $C_{L}$ and $C_{D}$ are drags and lift coefficients, $\rho$ is the fluid density, $V$ is the object velocity and $A$ being the frontal area projected. All of the annotations are distributed from the car body as shown in Figure 3. As a normal car produces lift at the rear end, an analysis of how much drag the car body can produce at different speeds is a main concern in this paper. The subdivision of drag is according to the regions on the body vehicle. However, the consideration of this type's classification is more difficult than an actual car [19-21], due to pressure and shear stresses that are not known with the resolution needed. Based on the Ahmed body [20], for a generic car it can be divided into local drag contributions. Four geometric zones were distinguished for smooth body without attachment, there were [10]; Front end, the rear slant, the base (i.e., vertical plane at the rear), the side panels and roof and under body. In three dimensional views, the affected zones [20] for drag are as in Figure 4.

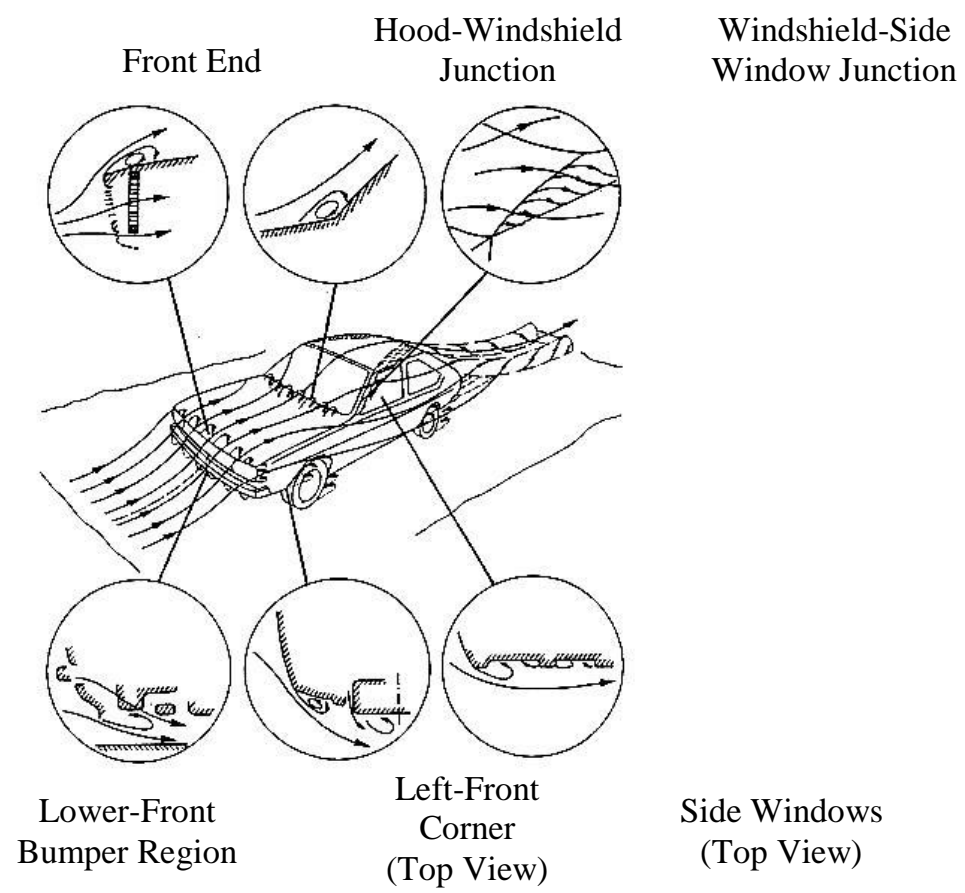

Figure 4. Flow around a car, and major locations of flow separation. 
The main concern for upper body is from the front-end bonnet (hood) until the rear end (boot) or base area. Streamlines as imaginary lines of flow can be visualised as a pattern of air movement on the body vehicle. The Bernoulli equation theory or Venturi effect can be the basis of explanation for the streamline of air velocity and the pressure over the car's body [9, 22-24]. Since the car body was modelled in CAD and refined, the next stage imported the CAD model into CFD software. CFD analysis was run with the COSMOSFloWorks ${ }^{\mathrm{tm}}$ software [25]. At this stage, various car speeds were analysed ranging at speeds of $40 \mathrm{~km} / \mathrm{h}$ to $110 \mathrm{~km} / \mathrm{h}$ for every interval of $10 \mathrm{~km} / \mathrm{h}$. The boundary condition for this analysis is the external flow with velocity moving over the car. Besides that, the types of flow considered are a mixture of laminar and turbulent flow for CFD model analysis. Figure 5 below shows the boundary for analysis of CFD.

A strategy to mesh the model was by making automatic mesh analysis using CosmosFloWorks ${ }^{\mathrm{tm}}$ adaptive meshing capabilities. The mesh was enhanced when iterations were increased at 10, 50, and 100 iterations. This increased the mesh count and narrowed the mesh location on different parts of the car more accurately to represent the flow. The results of the CFD analysis are then transferred to FEM by means of mesh distributions.

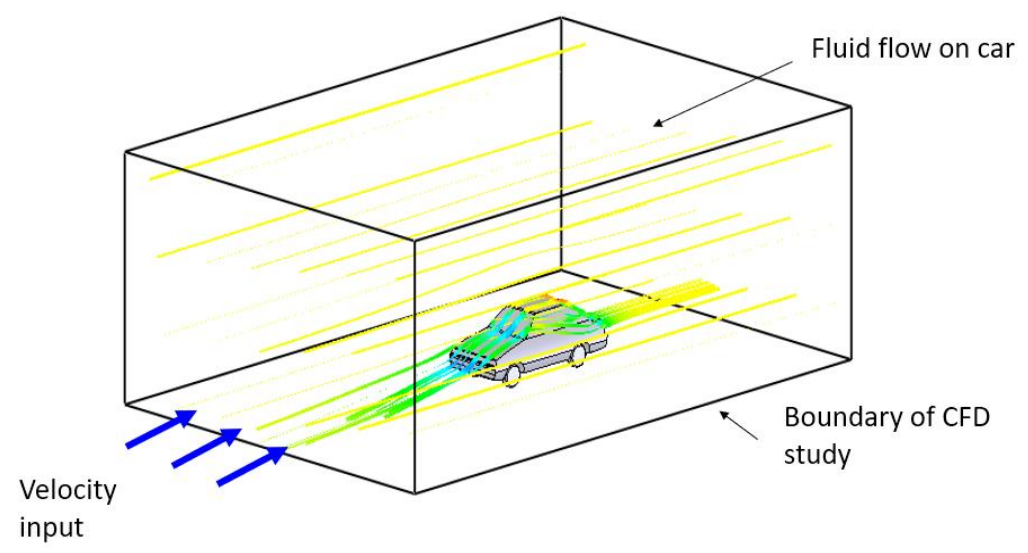

Figure 5. Boundary Condition of CFD analysis.

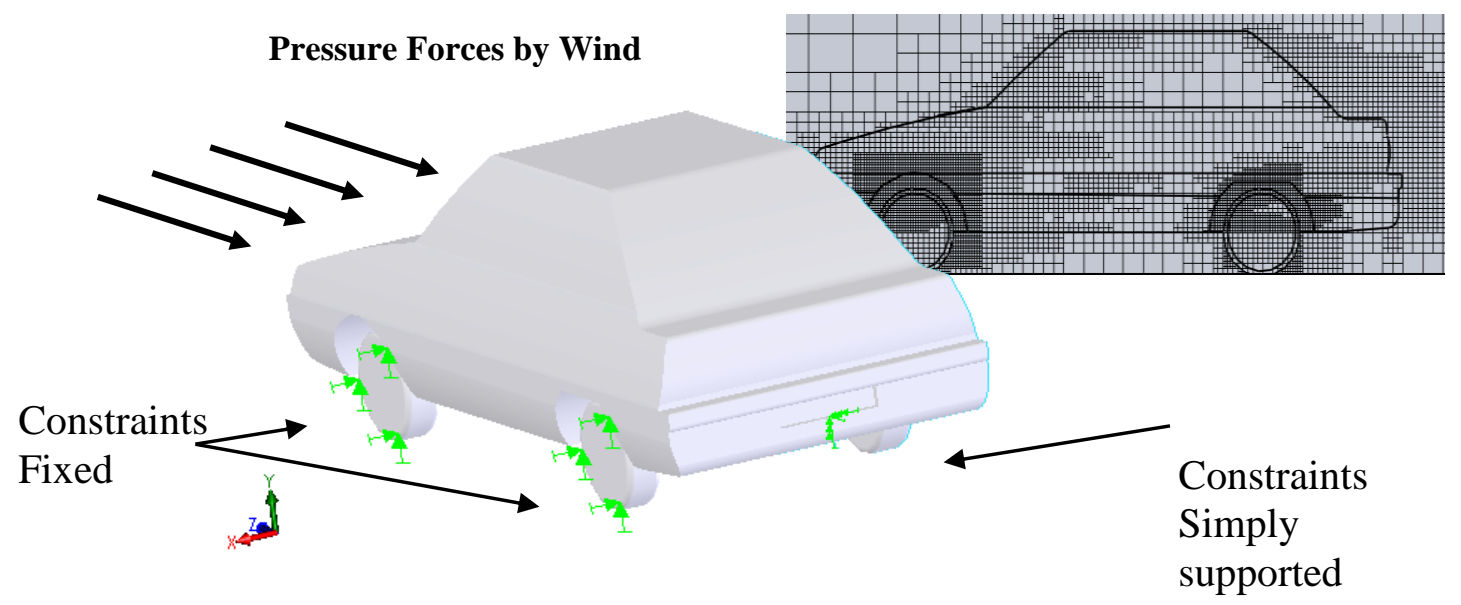

Figure 6. Constraints of FEM analysis as in a wind tunnel with meshing. 
To find the drag force, FEM analysis assumed as a rigid body by way of a concept consisting of wind tunnel for finite element analysis software was used. All four vehicles' wheels were made constraining which cannot move upwards (vertically to Y-axis) and sideward (horizontally to X-axis). In addition, the constraint of fixed point at the rear applying as weld joint. Thus, the model will be supporting the pressure force by wind in an opposite direction of Z-axis as shown in Figure 6. A three-dimensional Tetramesh was applied to gather all the forces calculated by the CFD software. The mesh enables for new calculation of the drag exerted by wind forces as shown in Figure 6.

\section{DESIGN VALIDATION}

After running the simulation on CFD and FEM analysis, the experiment as shown in Figure 7 validates the simulation analysis results. The validation scope aims to get the value of total pressure at a certain point on the body of Proton Iswara $[10,26,27]$ The tools used for the analysis were data acquisition from DATAQ Instruments Hardware Manager Device and WINDAQ Acquisition Software, Honeywell pressure transducers, static pressure pads and a connecting box.

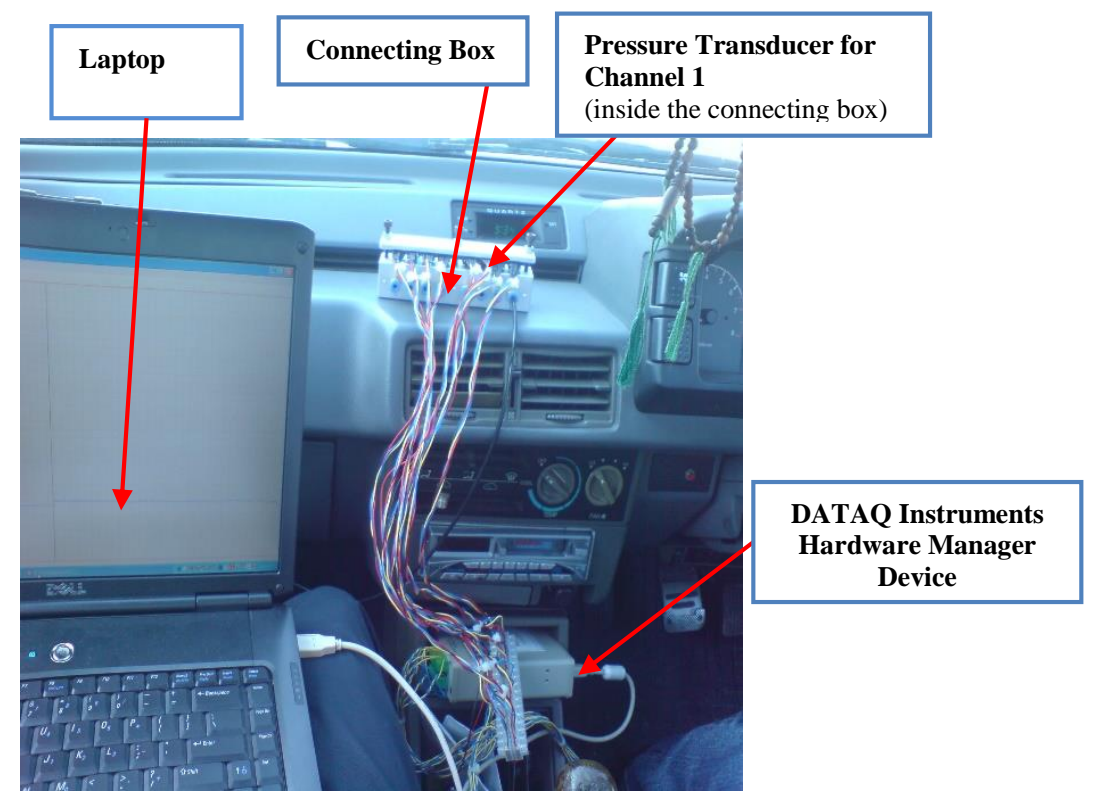

Figure 7. The experiment tools setup.

The experiment was performed along a straight road outside the laboratory of Universiti Malaysia Pahang. The speed tests of experiment are $40 \mathrm{~km} / \mathrm{h}$ and $50 \mathrm{~km} / \mathrm{h}$ only, followed by the gauge pressure measured by the experiment tools. The pressure pad was located at four different point locations from the Ahmed Body [20], Front End Bumper, Bottom of Windshield, Front End Roof, and Rear End Roof.

\section{RESULTS AND DISCUSSION}

From Figure 8, the curve follows a positive quadratic form graph. It shows that the drag force, $\mathrm{D}$ is the function to the square of velocity in the range specified. Thus, the increase of velocity would affect the increase of drag force. 


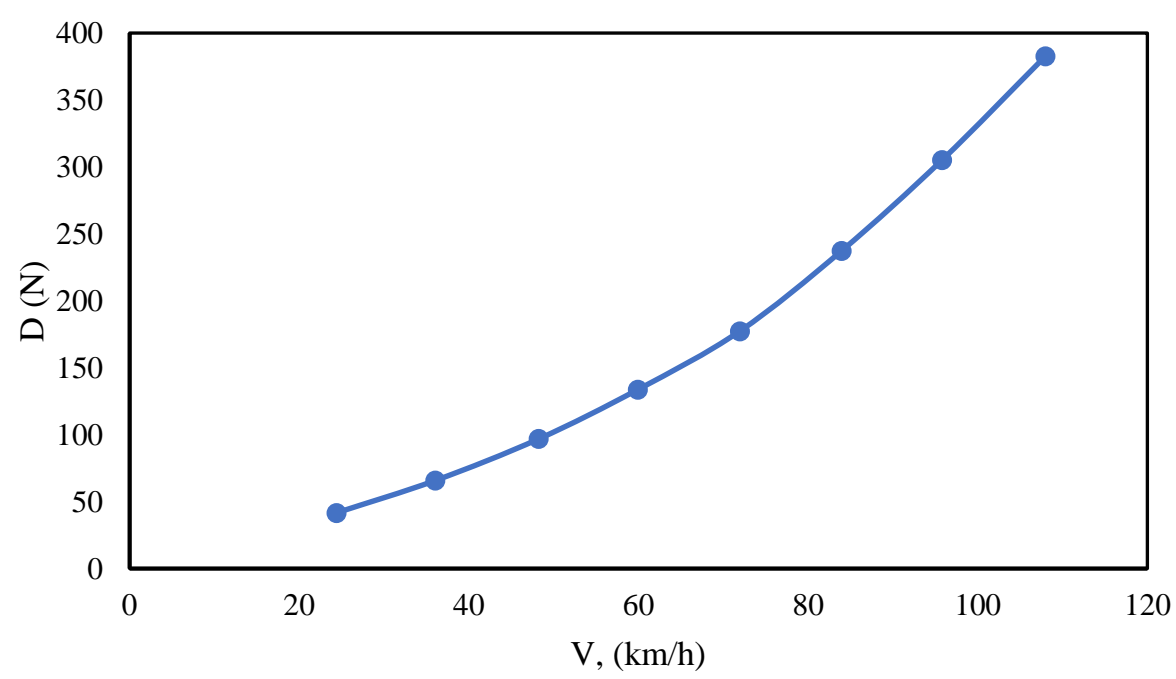

Figure 8. Variation of drag force against velocity.

The percentage rises of aerodynamics drag in terms of drag coefficient for ranging the velocity's analysis between $40 \mathrm{~km} / \mathrm{h}$ to $110 \mathrm{~km} / \mathrm{h}$ are is in Figure 9 . The graph shows that for $40 \mathrm{~km} / \mathrm{h}$ to $80 \mathrm{~km} / \mathrm{h}$, the average percentages of aerodynamics drag rises are about $1.2 \%$, where there is no significant change of aerodynamics drag at that range but the aerodynamics drag was already built at the range of velocity.

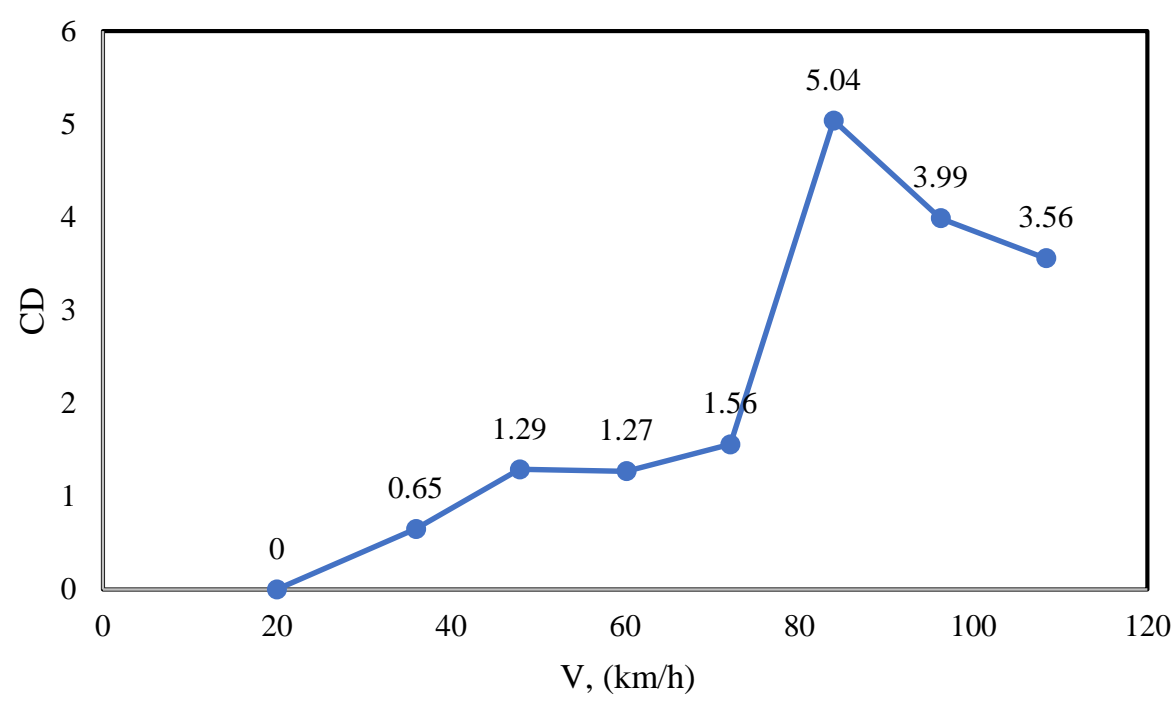

Figure $9 . C_{D}$ rises percentages against velocity.

The percentage of aerodynamics drag was changing drastically at a velocity of 90 $\mathrm{km} / \mathrm{h}$ at about $5.04 \%$. It then gradually decreased at the speed range of $90 \mathrm{~km} / \mathrm{h}$ to 110 $\mathrm{km} / \mathrm{h}$ at $3.99 \%$ and $3.56 \%$. Since the value of drag coefficients at $100 \mathrm{~km} / \mathrm{h}$ and $110 \mathrm{~km} / \mathrm{h}$ are higher, it does not mean that the percentage rises of drag coefficient were increased. This is because, the high speed of $100 \mathrm{~km} / \mathrm{h}$ and $110 \mathrm{~km} / \mathrm{h}$, the aerodynamics streamline were fully developed more than the velocity of $90 \mathrm{~km} / \mathrm{h}$. Figure 10 shows the actual results of $C_{D}$ obtained for different speeds. The highest $C_{D}$ is at $110 \mathrm{~km} / \mathrm{h}$ of 0.356 . 


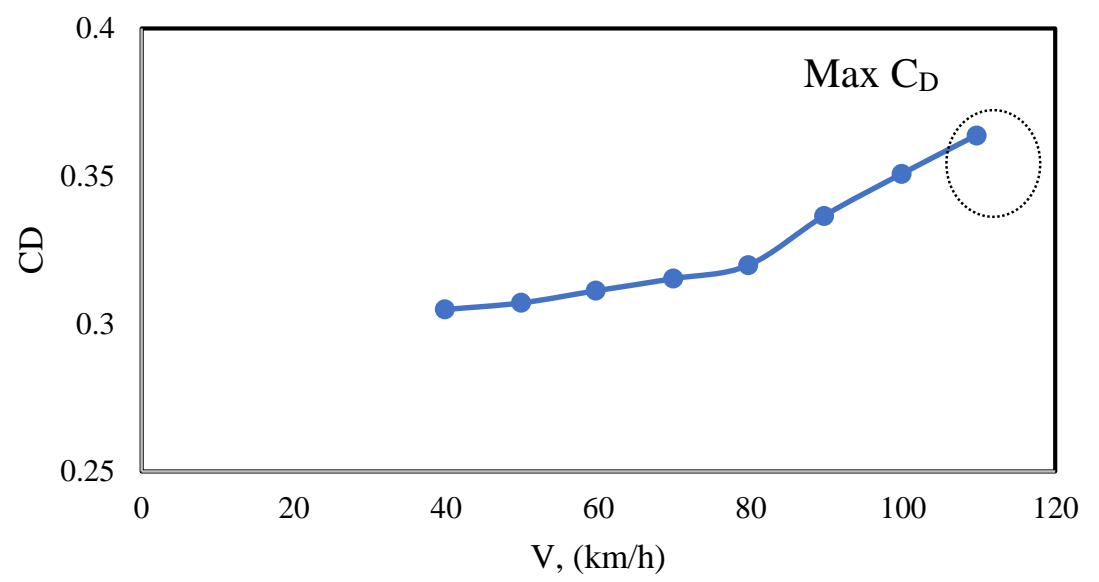

Figure 10. Effect of $C_{D}$ against velocity.

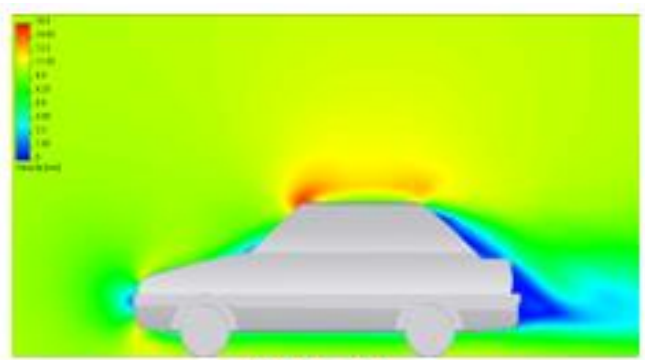

$40 \mathrm{~km} / \mathrm{h}$

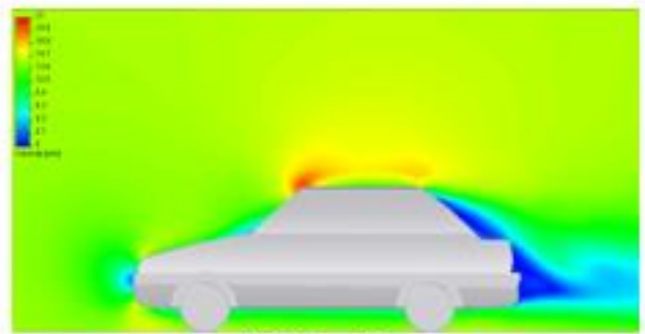

$50 \mathrm{~km} / \mathrm{h}$

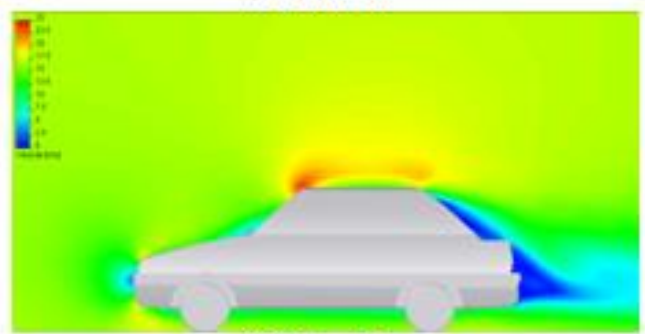

$60 \mathrm{~km} / \mathrm{h}$

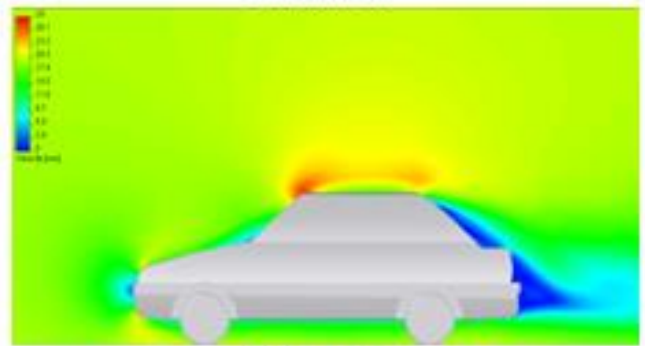

$70 \mathrm{~km} / \mathrm{h}$

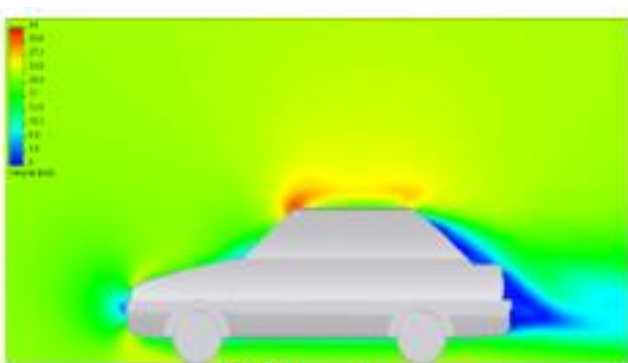

$90 \mathrm{~km} / \mathrm{h}$

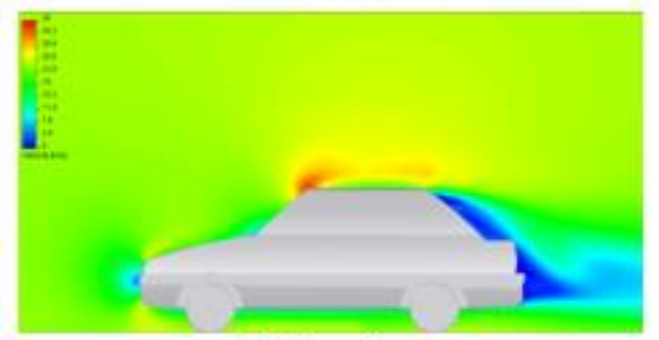

$90 \mathrm{~km} / \mathrm{h}$

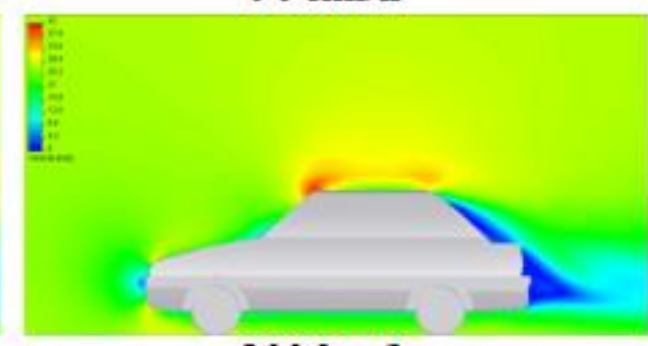

$100 \mathrm{~km} / \mathrm{h}$

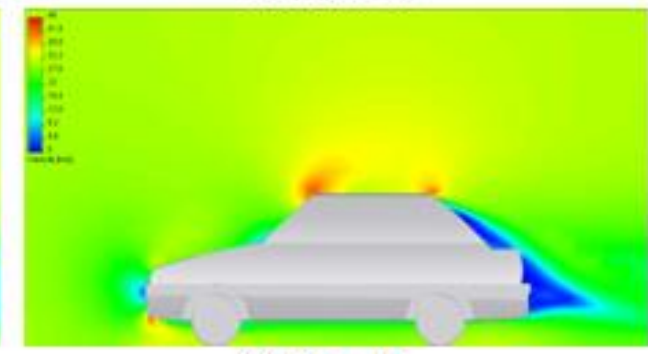

$110 \mathrm{~km} / \mathrm{h}$

Figure 11. Table of velocity contour plot from the centre body for various velocities. 


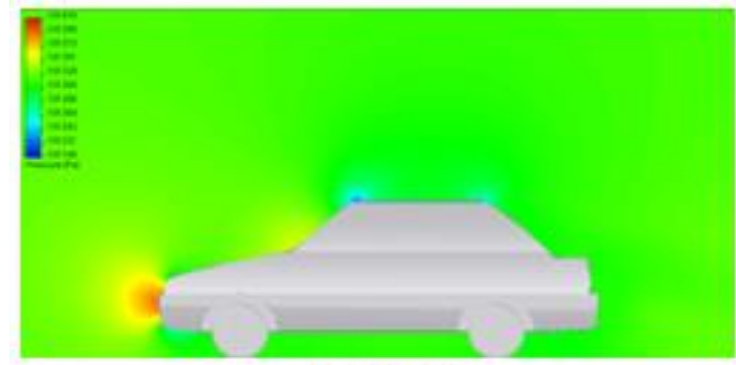

$40 \mathrm{~km} / \mathrm{h}$

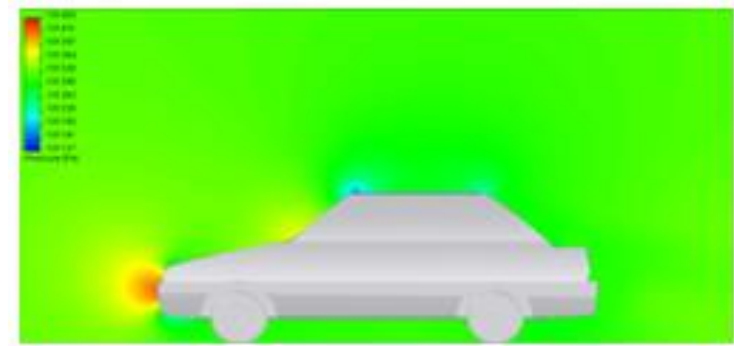

$50 \mathrm{~km} / \mathrm{h}$

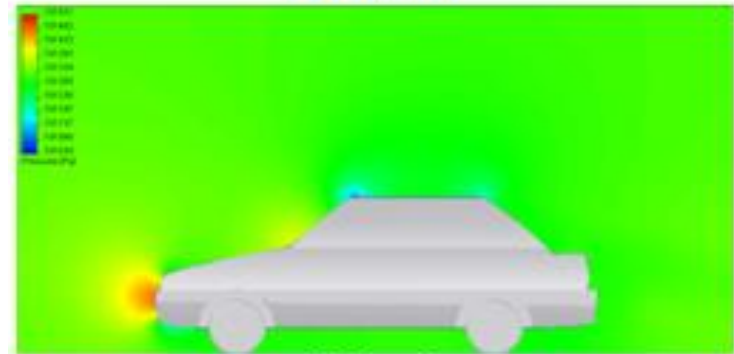

$60 \mathrm{~km} / \mathrm{h}$

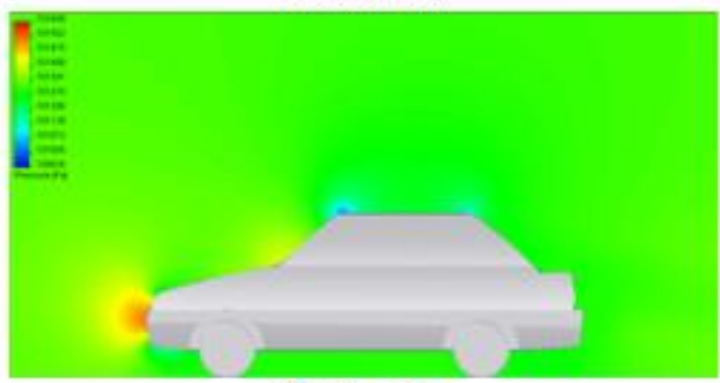

$70 \mathrm{~km} / \mathrm{h}$

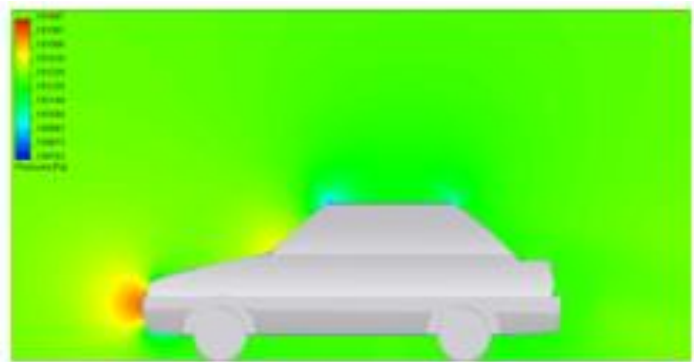

$80 \mathrm{~km} / \mathrm{h}$

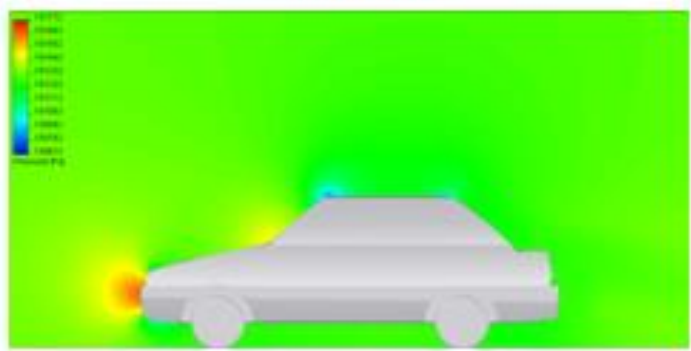

$90 \mathrm{~km} / \mathrm{h}$

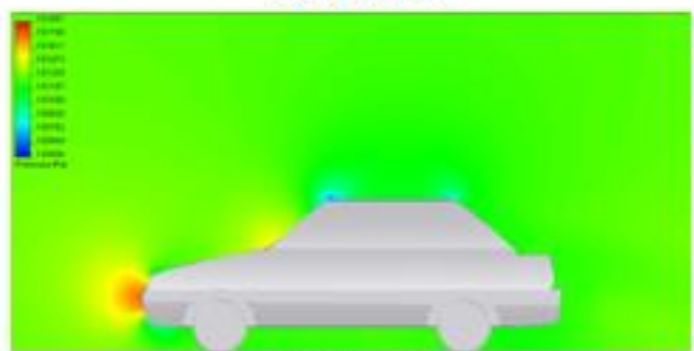

$100 \mathrm{~km} / \mathrm{h}$

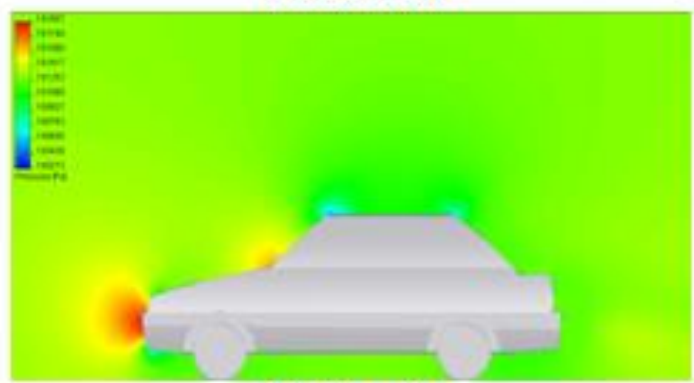

$110 \mathrm{~km} / \mathrm{h}$

Figure 12. Table of pressure contour plot from the centre body for various velocities.

Figure 11 shows the contour plot of velocity for the ranging analysis. From the figure, the contour plot of velocity was quite similar for every velocity of the analysis. The red and blue colours from the contour plot of velocity show high and low velocities. A slight difference in the contour plot of velocity is seen at the high velocity of $110 \mathrm{~km} / \mathrm{h}$. A clear difference can be seen at the blue region behind the body called as a wake region, where the turbulent flows were built after laminar flow from the separation point located at above rear windshield or at the rear end edge of roof. The wake region or blue colour is small than another, showing better separation flow from the streamline of fore body. At $90 \mathrm{~km} / \mathrm{h}$, the wake or separation region is clearly different, where the intensity of blue colour is more than the others and has a big of region. It shows the base pressure drag is high and affects the increasing drag force. At the same time as, it shows the rationalisation of analysis based on Figure 9. 
For Figure 12, the contour plot for pressure was considered to identify the effect of the drag [21]. The red colours developed at the end of front bumper indicated the high dynamics pressure known as stagnation point as velocity was reduced to zero. Meanwhile, the blue colour at the two end-points of the roof's body show a negative or low of pressure distribution. This is due to the high of streamline velocity during convergence and divergence wedge of air flow on top of the body that can be seen from Figure 11. The local pressure depicts clearly the difference of the velocity of $110 \mathrm{~km} / \mathrm{h}$, where the yellow colour is more apparent than the green colour for other velocity analyses. The yellow colour means high pressure drag or high of drag coefficient. Besides that, the big red colour of stagnation point means high dynamics pressure, which also gives a significant value for the aerodynamics drag [28]. Based on the experiment and simulation results, the absolute value of pressure was plotted in Figure 13. The differences between the experiment and simulation results were also calculated to define the validation between the experiment and simulation results at specific vehicle speeds of $40 \mathrm{~km} / \mathrm{h}$ and $50 \mathrm{~km} / \mathrm{h}$. Figure 13 shows the data of pressure read from the experiment and simulation for various point locations at $40 \mathrm{~km} / \mathrm{h}$. Both data sets were represented by the differences for front end bumper at $0.05 \%$ the bottom windshield at $0.01 \%$, the front end roof at $0.07 \%$, and the rear end roof at $0.06 \%$. The highest differences between the experiment and simulation data analysis were expected from the inaccuracy of CAD modelling at a certain body and lack of meshing in CFD simulation analysis. The error is persistent, and this is due to the nature of simulations which over predict the actual data $[29,30]$. The data from simulation are ideal and do not consider the real life turbulence and heat from the air from the time of the day.

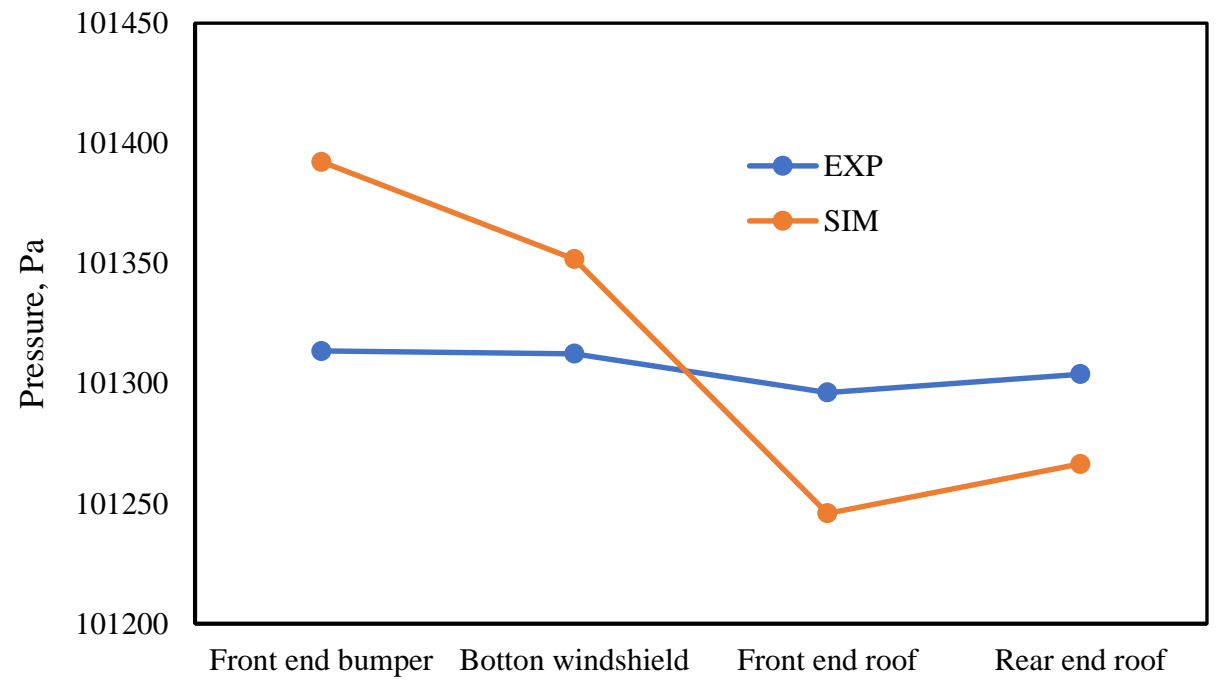

Figure 13. Variation of pressure against various point locations for speed $40 \mathrm{~km} / \mathrm{h}$.

\section{CONCLUSIONS}

The main objective of this study which is to estimate the drag coefficient and flow visualisation is achieved. Aerodynamics drag for Proton Iswara's body was obtained at 0.326 at ranging velocities between $40 \mathrm{~km} / \mathrm{h}$ and $110 \mathrm{~km} / \mathrm{h}$ for every $10 \mathrm{~km} / \mathrm{h}$ analysis. The analysis shows aerodynamics drag in terms of drag forces or drag coefficient increased to the square of velocity for Proton Iswara's body, which has a frontal area of $1.84 \mathrm{~m}^{2}$. The maximum rise of aerodynamics drag occurred between velocities of $80 \mathrm{~km} / \mathrm{h}$ 
and $90 \mathrm{~km} / \mathrm{h}$ which is about of $5.04 \%$ of increase of drag coefficient. The contour plot of velocity and pressure was shown in aerodynamics drag analysis as a visualisation analysis. The pattern of visualisation for every velocity depicted similarly, either for velocity contour plot or pressure contour plot. However, at $90 \mathrm{~km} / \mathrm{h}$ and $110 \mathrm{~km} / \mathrm{h}$, the plot of velocities obviously shows variation. Therefore, some recommendations were discussed to improve this analysis for better performance on the HEV model design. First is to use a proper experimental analysis using a wind tunnel to validate the simulation analysis. Second is to refine the model geometry dimensions by 3D scanner to get better accuracy during CFD and FEM analysis on Proton Iswara. The actual model will be tested on a vehicle in the wind tunnels.

\section{ACKNOWLEDGEMENTS}

The authors would like to be obliged to University Malaysia Pahang for providing laboratory facilities and financial assistance under project RDU 160319.

\section{REFERENCES}

[1] Zulkifli SA, Mohd S, Saad N, A. Aziz AR. Operation and control of split-parallel, through-the- road hybrid electric vehicle with in-wheel motors. International Journal of Automotive and Mechanical Engineering. 2015;11:2793-808.

[2] Salisa AR, Walker PD, Zhang N, Zhu JG. Comparative cost-based analysis of a novel plug-in hybrid electric vehicle with conventional and hybrid electric vehicles. International Journal of Automotive and Mechanical Engineering. 2015;11:2262-71.

[3] Salleh I, Md. Zain MZ, Raja Hamzah RI. Evaluation of annoyance and suitability of a back-up warning sound for electric vehicles. International Journal of Automotive and Mechanical Engineering. 2013;8:1267-77.

[4] Rahmat MS, Ahmad F, Mat Yamin AK, Aparow VR, Tamaldin N. Modeling and torque tracking control of permanent magnet synchronous motor (PMSM) for hybrid electric vehicle. International Journal of Automotive and Mechanical Engineering. 2013;7:955-67.

[5] Wahono B, Nur A, Santoso WB, Praptijanto A. A comparison study of rangeextended engines for electric vehicle based on vehicle simulator. Journal of Mechanical Engineering and Sciences. 2016;10:1803-16.

[6] Omar SMHS, Arshad NM, Yassin IM, Fakharuzi MHAM, Ward TA. Design and optimization of powertrain system for prototype fuel cell electric vehicle. Journal of Mechanical Engineering and Sciences. 2015;8:1401-13.

[7] Mohd TAT, Hassan MK, A. Aziz WMK. Mathematical modeling and simulation of an electric vehicle. Journal of Mechanical Engineering and Sciences. 2015;8:1312-21.

[8] Rosli AB, Ramasamy D. Design and Development of Hybrid Electric Vehicle Rear Diffuser. Science, Technology \& Social Sciences (STSS). Kuantan, Pahang, Malaysia: Universiti Malaysia Perlis; 2008.

[9] Lombardi G, Beux F, Carmassi S. Aerodynamic Design of High Performance Cars: Discussion and Examples on the Use of Optimization Procedures. SAE Technical Paper; 2002.

[10] Iaccarino L. Cranfield University Formula 1 Team: An Aerodynamics Study of the Cockpit. School of Engineering Cranfield University; 2003. 
[11] Sahid N, Rahman M, Kadirgama K, Ramasamy D, Maleque M, Noor M. Experimental investigation on the performance of the $\mathrm{TiO}_{2}$ and $\mathrm{ZnO}$ hybrid nanocoolant in ethylene glycol mixture towards AA6061-T6 machining. International Journal of Automotive \& Mechanical Engineering. 2017; 14:391326.

[12] Okolo PN. Computational Fluid Dynamics (CFD) Modeling Of Turbulence Induced Drag In Vehicle Aerodynamics 2017.

[13] Afroz F, Lang A, Jones E. Use of a rotating cylinder to induce laminar and turbulent separation over a flat plate. Fluid Dynamics Research. 2017;49:035509.

[14] Wong H.M DR. Series Hybrid Electric Vehicle Cost-Effective Powertrain Components Development. In: UMP, editor. RDU 070305. Pahang: Universiti Malaysia pahang; 2007. p. 1.

[15] Drayton MCaS. Proton Service and Repair Manual. USA: Haynes Ptd. Ltd; 2003.

[16] Shidique A. Simulation and analysis of hybrid electric vehicle (HEV) by addition of a front spoiler, p39: Thesis, Universiti Malaysia Pahang; 2007.

[17] Yogeswaran M, Kadirgama K, Rahman M, Devarajan R, Noor M. Effect of ZnO nano materials on grinding surface finishing. International Journal of Automotive and Mechanical Engineering. 2015; 12:2829-43.

[18] Hucho W-H. Aerodynamics of road vehicles: from fluid mechanics to vehicle engineering; 2013.

[19] Munson BR, Young DF, Okiishi TH. Fundamentals of fluid mechanics: New York; 1990.

[20] Sumantran DV, Sovran DG. Vehicle Aerodynamics. Warrendale, PA: Society of Automotive Engineers; 1996.

[21] Anderson JD. Introduction to flight: McGraw-Hill Boston; 2005.

[22] Heisler H. Advanced vehicle technology: Elsevier; 2002.

[23] Koike M, Nagayoshi T, Hamamoto N. Research on aerodynamic drag reduction by vortex generators. Mitshubishi Motors Technical Review. 2004.

[24] Guilmineau E. Computational study of flow around a simplified car body. Journal of Wind Engineering and Industrial Aerodynamics. 2008;96:1207-17.

[25] Matsson JE. An Introduction to COSMOSFloWorks 2008: Schroff Development Corporation; 2008.

[26] Kleber A. Simulation of air flow around an Opel Astra vehicle with FLUENT. Journal Article, International Technical Development Center Adam Opel AG. 2001.

[27] Ramasamy D, Yuan GC, Bakar RA, Zainal Z. Validation of road load characteristic of a sub-compact vehicle by engine operation. International Journal of Automotive and Mechanical Engineering. 2014;9:1820-31.

[28] García J, Muñoz-Paniagua J, Crespo A. Numerical study of the aerodynamics of a full scale train under turbulent wind conditions, including surface roughness effects. Journal of Fluids and Structures. 2017;74:1-18.

[29] Zhang D, Ivanco A, Filipi Z. Model-Based Estimation of Vehicle Aerodynamic Drag and Rolling Resistance. SAE International Journal of Commercial Vehicles. 2015;8:433-9.

[30] Ramasamy D, Kadirgama K, Rahman M, Zainal Z. Analysis of compressed natural gas burn rate and flame propagation on a sub-compact vehicle engine. International Journal of Automotive and Mechanical Engineering. 2015;11:240516. 